\title{
Patient-reported respiratory symptoms and pre- bronchodilator airflow limitation among smokers in Switzerland
}

\section{\#David Miedingera,b, \#Anette Linza, Claudia Praehausera, Prashant N Chhajeda, Christian Buess', Salome Schafroth Török, Heiner C Bucherb, Michael Tamma, *Jörg D Leuppia}

a Pulmonary Medicine, Department of Internal Medicine, University Hospital, Basel, Switzerland

${ }^{\mathrm{b}}$ Basel Institute for Clinical Epidemiology, University Hospital, Basel, Switzerland

c ndd Medizintechnik AG, Zürich, Switzerland

\# Joint first authors

Originally submitted 14th July 2009; resubmitted 12th October 2009; revised version received 11th January 2010;

final revised version received 7th March 2010; accepted 6th April 2010; online 31st May 2010

\begin{abstract}
Aims: To evaluate the prevalence and predictors of airflow limitation among smokers aged $\geq 40$ years visiting primary care practices in Switzerland, and the correlation between airflow limitation and patient-reported symptoms.

Methods: General practitioners (GPs) were invited to participate in the study via letter. Airflow limitation was measured using an EasyOne $^{\mathrm{TM}}$ spirometer without administration of a bronchodilator, and patient-reported symptoms were evaluated using an intervieweradministered questionnaire.

Results: 15,084 subjects recruited by 440 GPs had acceptable quality spirometry traces; 8,031 of these (53\%) had symptom data available and were included in this analysis. Only $18.5 \%$ of the GP consultations were for respiratory reasons. In total, $29 \%$ of individuals had prebronchodilator airflow limitation suggesting chronic obstructive pulmonary disease according to the Global Initiative for Chronic Obstructive Lung Disease (GOLD)/Hardie interpretation. The interviewer-administered questionnaire indicated that $58 \%$ of individuals had at least one current symptom - cough, sputum production, or dyspnoea. There were no differences in lung function for patients answering yes or no to symptom questions.

Conclusions: Pre-bronchodilator airflow limitation and patient-reported respiratory symptoms are frequent among smokers, but short dichotomous questions about symptoms are not useful for identifying patients with airflow limitation. Spirometry can identify patients with early airflow limitation in general practice. However, poor quality of spirometry, even with an automated feedback and quality control spirometer, remains an issue.

(C) 2010 Primary Care Respiratory Society UK. All rights reserved.

D Miedinger et al. Prim Care Resp J 2010; 19(2): 163-169

doi:10.4104/pcrj.2010.00030
\end{abstract}

Keywords smoking, general practice, chronic obstructive pulmonary disease, airflow limitation, spirometry, patient-reported symptoms

See linked editorial by Enright on page 91

\section{Introduction}

Chronic obstructive pulmonary disease (COPD) is a leading cause of morbidity and mortality worldwide. ${ }^{1}$ Its progressive nature makes early diagnosis and management particularly desirable.
However, in many cases the disease is not diagnosed until it is clinically apparent and moderately advanced. ${ }^{1,2}$ Early symptoms of COPD, such as breathlessness, are often dismissed and/or considered normal. As a consequence, identification of patients in the early stages of COPD is challenging.

Smoking remains the most important risk factor for COPD,

\footnotetext{
* Corresponding author: Dr Jörg D. Leuppi MD, PhD, Department of Internal Medicine, University Hospital, Petersgraben 4, 4031 Basel, Switzerland. Tel: +41612652525 Fax: +41612655353 E-mail: leuppij@uhbs.ch
} 
and smoking cessation is widely accepted as the single most effective - and cost-effective - intervention to reduce the risk of developing COPD and prevent its progression. ' Unfortunately, many patients find smoking cessation difficult. In the USA, for example, almost $41 \%$ of smokers try to quit smoking each year, but relapse is common, and only about $10 \%$ achieve and maintain abstinence. ${ }^{1}$ Spirometry has for a long time been proposed as a motivational tool to encourage smokers at risk of developing COPD to quit the habit, but data on its value as a supporting technique for smoking cessation are inconclusive., ${ }^{3,4}$

Screening at-risk patients in primary care represents a useful option for identifying individuals with early symptoms of COPD, thereby providing the opportunity to implement aggressive smoking cessation strategies. ${ }^{4,5}$ Spirometry has been shown to be an effective means of screening patients, thus increasing the probability of earlier diagnosis. A recent study of smokers aged $\geq 40$ years with no formal diagnosis of COPD in the UK and USA found that $18.9 \%$ fulfilled the criteria of COPD after performing spirometry by using the Global Initiative for Chronic Obstructive Lung Disease (GOLD) criteria; of these, $57 \%$ were classified as having mild, 37\% moderate and $6 \%$ severe obstruction. ${ }^{6}$ The authors concluded that screening smokers over 40 years old using spirometry in general practice may yield 10-20\% undiagnosed COPD cases, with a substantial proportion of these having moderate to severe disease. ${ }^{6}$ However, the quality of spirometry in primary care is a debated concern, and it is underused as a method for early detection.?

Alternatively, the use of symptom-based questionnaires has been proposed as a means of identifying persons likely to have COPD in the general population. ${ }^{8}$ Whether such questionnaires may also be used to pre-screen smokers to find those who should be tested with spirometry is questionable. ${ }^{9}$

We conducted a study to determine the quality of spirometry tracings made by general practitioners (GPs) who were provided with a spirometer, and to evaluate patient-reported symptoms and the prevalence of airflow limitation in participating smoking patients aged $\geq 40$ years making a visit for any reason to primary care in Switzerland. For this study, participating GPs were instructed in an introductory lesson how to use the spirometer and how to perform spirometry. GPs performed the spirometries in the context of automatic quality grading by the spirometers according to the National Lung Health Education Program (NLHEP) but without ongoing external quality control by the study team. The spirometry quality results were published recently. ${ }^{10} \mathrm{We}$ found that about $60 \%$ of the spirometry measurements were shown to have at least two reproducible measurements according to the NLHEP quality criteria and that airway obstruction was found in $27 \%$ of smokers aged $\geq 40$ years.

In this paper, we report the respiratory symptoms and prebronchodilator airway obstruction in a subgroup of study participants where GPs administered a short questionnaire regarding respiratory symptoms on the day of the examination prior to performing spirometry. Following helpful suggestions by the editor and reviewers of the Primary Care Respiratory Journal $(P C R J)$ we further analysed the data post-hoc to determine predictors for airway obstruction in smokers aged $\geq 40$ years by logistic regression analysis.

\section{Methods}

To recruit physicians we contacted 1,800 GPs at the address taken from a Swiss physician register (maintained by the Swiss Medical Association) using a one-off, bulk mailing of invitation letters. Four-hundred-and-forty GPs agreed to participate in this study. We did not contact non-respondents a second time. The EasyOne $^{\mathrm{TM}}$ spirometer (ndd Medizintechnik AG, Zurich, Switzerland) with disposable mouthpieces was offered without charge to participating physicians even if they had already performed spirometries in their office before. Physicians were allowed to keep the spirometer at the end of the study without charge. Those who agreed to participate responded by mail, and were contacted by the spirometry sales company to schedule the installation of the spirometer and instruction section. Before commencing the study, participating GPs and their practice nurses were instructed how to perform spirometry according to American Thoracic Society (ATS) guidelines by representatives of the spirometry sales company. ${ }^{11}$ This instruction took place at the GP's office and took approximately 1-2 hours. Physicians were asked to recruit at least 60 current smokers aged $\geq 40$ years, independent of the reason for consultation. No data were collected on previous spirometries or confirmed diagnoses.

The spirometer employed in the study had ultrasonic transittime flow measurement technology with built-in software for quality control and feedback for the examiner, and was factorycalibrated without the need for further calibration. All spirometry measurements were performed in a seated position and required the use of a nose clip. The quality of spirometry was assessed automatically by the spirometer, as recommended in the consensus statement from the NLHEP and using the grading recommended from that report. Spirometry data were classified into quality control grades $A$ to $D$ or $F$ using the criteria of Ferguson et al. ${ }^{12}$ In this study, we did not physically validate if the quality grades assigned to the spirometry by the spirometer were accurate. For the predicted values, the reference values by Brandli et al. (Swiss study on Air Pollution and Lung Diseases in Adults [SAPALDIA]) were used.$^{13}$ Interpretation of the spirometry data was performed by the authors according to the criteria of the GOLD committee and Hardie et al., ${ }^{1,14,15}$ with the exception that pre-bronchodilator data was used in the interest of simplicity. Accordingly, airflow limitation was defined as a prebronchodilator forced expiratory volume in one second $\left(\mathrm{FEV}_{1}\right) /$ forced vital capacity $(\mathrm{FVC})$ ratio $<0.7$ in patients younger than 70 years of age, $\mathrm{FEV}_{1} / \mathrm{FVC}$ ratio $<0.65$ in patients between 
70-80 years of age, and $\mathrm{FEV}_{1} / \mathrm{FVC}$ ratio $<0.6$ in patients older than 80 years of age. Possible restriction was assigned if $\mathrm{FEV}_{1} / \mathrm{FVC}$ was above the age-adjusted threshold values but the measured FVC was less than the lower limit of normal (LLN) and $\mathrm{FEV}_{1}$ less than the LLN of predicted values.

\section{Questionnaire}

For collection of symptom data, GPs administered a brief unvalidated questionnaire regarding current respiratory symptoms. The questions were 'Do you cough?' (yes/no) and 'Do you have sputum production?' (yes/no), and patients were asked about the severity of dyspnoea according to the ATS modified Medical Research Council (MRC) dyspnoea score. 16,17 The severity was rated on a 5-point scale: 0 . 'Not troubled by breathlessness except on strenuous exercise'; 1 . 'Short of breath when hurrying or walking up a slight hill'; 2. 'Walks slower than contemporaries on the level because of breathlessness, or has to stop for breath when walking at own pace'; 3. 'Stops for breath after about $100 \mathrm{~m}$ or after a few minutes on the level'; and 4. 'Too breathless to leave the house, or breathless when dressing or undressing'. GPs were given instructions to ask patients about their current symptoms, but no instructions on asking how long the symptoms had been present. We distributed the questionnaire pre-printed on a separate, otherwise blank, print-out sheet. GPs were asked to fill out the questionnaire during the consultation and prior to performing spirometry. The spirometry results were then printed on this sheet, and collected by the study investigators for data collection and entry. In addition, the participating physician was asked to categorise the main reason for the patient's visit. The categories included musculoskeletal system, cardiovascular system, respiratory system, gastrointestinal tract and others.

\section{Statistical analyses}

Continuous variables are expressed as means with standard deviation [SD] or $95 \%$ confidence intervals (CI), and categorical variables are expressed as relative frequencies and percentages. Proportions were compared by using chi-square analysis. As suggested by one of the $P C R J$ reviewers, we performed post-hoc logistic regression analysis in the sub-dataset of patients with quality grade $\mathrm{A}-\mathrm{C}$ in whom reproducible spirometries were available. Clinically important airway obstruction ( $\left.\mathrm{FEV}_{1} / \mathrm{FVC}<0.7\right)$ and $\mathrm{FEV}_{1}<65 \%$ predicted were used as dependent variables. We included age (continuous variable), sex (male vs. female), obesity $\left(\geq 30 \mathrm{~kg} / \mathrm{m}^{2} \mathrm{vs} .<30 \mathrm{~kg} / \mathrm{m}^{2}\right.$ ), GP having collected symptom data (yes vs. no), consultation reason (respiratory vs. musculoskeletal vs. cardiovascular gastrointestinal vs. other), number of spirometries performed by the GP prior to this spirometry test (continuous variable), MRC dyspnoea level (level 0-2 vs. level 3-4), having cough (yes vs. no), and having sputum (yes vs. no), as independent variables. The values of the continuous variables, age and number of tests performed by the GP were divided by 10 prior to analysis. The independent variable 'GP having collected symptom data' was excluded post-hoc due to co-linearity with other variables in the model. We considered a p-value of $<0.05$ as statistically significant. Analysis was performed with SPSS ${ }^{\circledR}$ version 14 and Microsoft ${ }^{\oplus}$ Office Excel 2008 software.

\section{Results}

Four-hundred-and-forty GPs agreed to participate in the study and 30,991 tests were downloaded from the participating GPs' spirometry devices. After excluding repeated tests in the same subjects (where the lower quality grades were deleted), 29,817 tests were available for the analysis of spirometry quality that has been published previously. ${ }^{10}$ Tests of subjects aged $<40$ years and of those who were not smoking were then excluded, leaving 24,995 tests. We then further excluded tests in individuals with low quality spirometry tracings (D, F). Spirometric measurements of 15,084 subjects $(60 \%)$ were at an acceptable quality grade ( $55 \%$ grade $A, 13 \%$ grade $B$ and $32 \%$ grade C). Additional data on symptoms and the reason for the consultation were obtained for 8,301 (55\%) subjects who had an acceptable spirometry quality grade - who were then included into this analysis. Age and body mass index (BMI) data are presented in Table 1. The mean age of patients was 54 years (range 40-90 years) and the mean BMI was $25.6 \mathrm{~kg} / \mathrm{m}^{2}$. Of the consultations, $18.5 \%$ were for reasons pertaining to the respiratory system. Other reasons for the consultation included cardiovascular system (16.7\%), musculoskeletal system (15.8\%), gastrointestinal system (4.1\%) and other reasons (44.9\%).

While approximately two-thirds of subjects showed no airflow limitation on their spirometry recording, 29\% had airflow limitation as measured according to the GOLD/Hardie interpretation, ${ }^{1,14,15}$ and $4 \%$ had spirometry values indicating possible restrictive disease (see Table 2).

The interviewer-administered questionnaire indicated that

\section{Table 1. Baseline patient information.}

\begin{tabular}{lc} 
& $\mathrm{n}(\%)$ \\
\hline Age distribution (years) & $8301(100)$ \\
$40-49$ & $3181(38.3)$ \\
$50-59$ & $2655(32.0)$ \\
$60-69$ & $1619(19.5)$ \\
$>70$ & $846(10.2)$ \\
\hline BMI (kg/m²) & \\
Normal (BMI 18.5-24.9) & $3578(45.1)$ \\
Pre-obese (BMI 25.0-29.9) & $2784(35.1)$ \\
Obese (BMI $\geq 30.0)$ & $1307(16.5)$ \\
Underweight (BMI <18.5) & $257(3.2)$ \\
Missing data & $375(4.5)$ \\
\hline Gender & \\
Male & $4716(57)$ \\
Female & $3585(43)$ \\
\hline BMI: body mass index. &
\end{tabular}


D Miedinger et al.

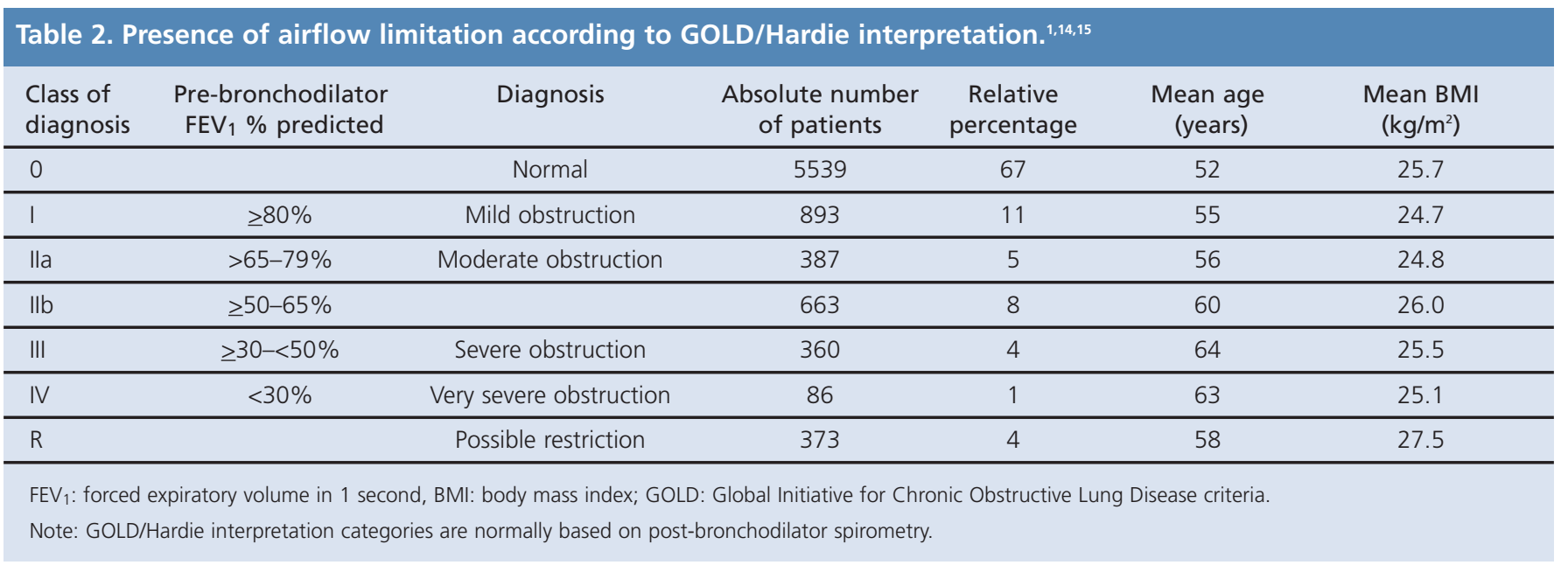

\begin{tabular}{|c|c|}
\hline Symptoms & n (\%) \\
\hline \begin{tabular}{l|l} 
Total reporting $\geq 1$ symptom
\end{tabular} & $4781(58)$ \\
\hline Cough & $3432(41)$ \\
\hline Sputum & $2284(27)$ \\
\hline Dyspnoea (MRC) $\geq$ level 1 & $3288(40)$ \\
\hline Level 1 & $2155(26)$ \\
\hline Level 2 & $859(10)$ \\
\hline Level 3 & $235(3)$ \\
\hline Level 4 & $39(0.5)$ \\
\hline
\end{tabular}

$58 \%$ of individuals had at least one symptom (cough, sputum) or an MRC dyspnoea level of $\geq 1$. A similar proportion of patients reported cough and/or dyspnoea (41\% and $40 \%$ of patients, respectively), while $27 \%$ reported sputum production (Table 3 ). Lung function did not differ significantly in individuals with or without cough: $\mathrm{FEV}_{1} \%$ predicted in those with cough was 80.9\% [95\% Cl: 80.3-81.4\%] and in those without cough was 81.8\% [95\% Cl: 81.4-82.3\%]; FEV $1 / F V C \%$ in those without cough was 95.9\% [95\% Cl: 95.6-96.3\%] and in those with cough $96.1 \%$ [95\% Cl: 95.8-96.4\%]. The same was true for sputum production: $\mathrm{FEV}_{1} \%$ predicted in those with sputum production was $81.0 \%$ [95\% Cl: 80.4-81.7\%] and in those with no sputum $81.7 \%$ [95\% Cl: 81.3-82.0\%]; $\mathrm{FEV}_{1} / \mathrm{FVC} \%$ predicted in those with sputum was $95.9 \%[95 \% \mathrm{Cl}$ : 95.5-96.3\%) and in those with no sputum $96.1 \%(95 \% \mathrm{Cl}$ : 95.8-96.3\%]). Lung function did not differ significantly in individuals with different levels of dyspnoea ( $\mathrm{FEV}_{1} \%$ predicted: Level 0: 81.5\% [95 \% Cl: 81.1-81.9\%]; Level $181.6 \%$ [95 \% Cl: 81.0-82.3\%]; Level 2 81.0\% [95 \% Cl: 79.9-82.0\%]; Level 3 81.3\% [95 \% Cl: 79.2-83.3\%]; and Level 4 82.4\% [95\% Cl: $77.1-87.7 \%])$.
Figure 1. Level of dyspnoea by airflow limitation; 0=normal, l=mild obstruction, Il=moderate obstruction, III=severe obstruction, IV=very severe obstruction.

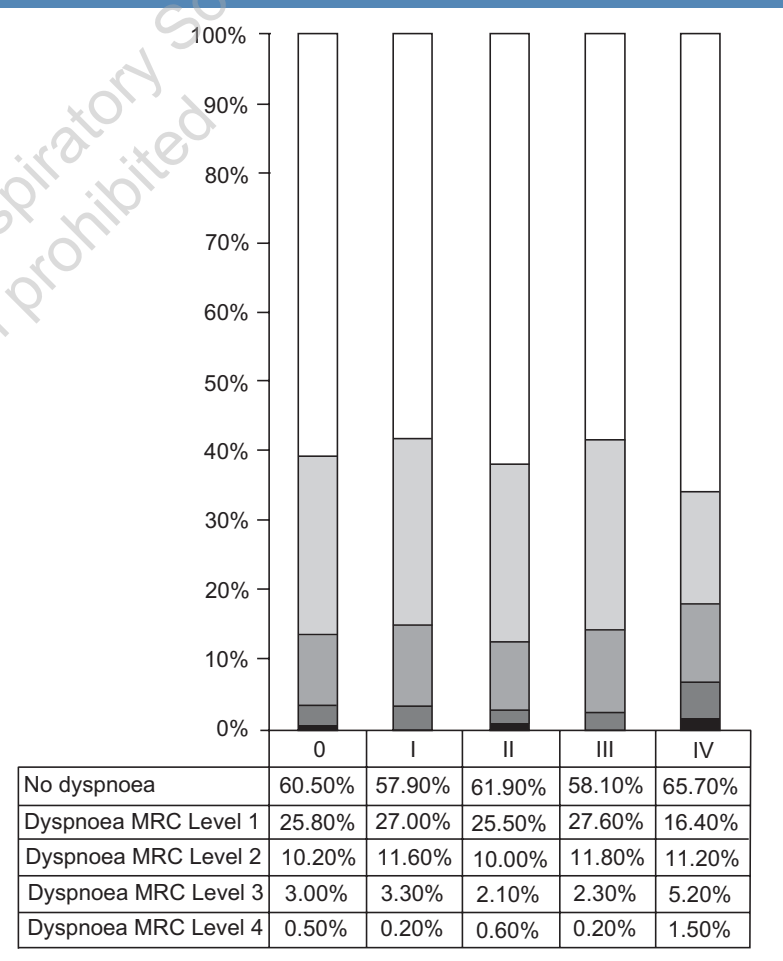

Little difference was found in the level of dyspnoea when classifying individuals regarding the grade of airflow limitation according to the GOLD/Hardie classification. Only the subgroup with severe and very severe obstruction tended to have more severe dyspnoea (Figure 1) although due to the small number of individuals in this sub-group it did not reach statistical significance $(p=0.175)$. There was, however, no correlation between the number of symptoms reported and lung function, and asymptomatic and symptomatic subjects were equally likely to present with any level of airflow 
Table 4. Logistic regression to determine factors that contribute to clinically relevant airway obstruction (low $\mathrm{FEV}_{1} / \mathrm{FVC}$ ratio and $\mathrm{FEV}_{1} \%$ predicted below $65 \%$ ).

\begin{tabular}{lccc} 
Co-variates & $\begin{array}{l}\text { Odds } \\
\text { ratio }\end{array}$ & $\begin{array}{c}\text { Lower } \\
95 \% \mathrm{Cl}\end{array}$ & $\begin{array}{l}\text { Upper } \\
95 \% \mathrm{Cl}\end{array}$ \\
\hline $\begin{array}{l}\text { Age (per 10 } \\
\text { year increment) }\end{array}$ & 1.99 & 1.89 & 2.10 \\
\hline Female sex & 0.78 & 0.69 & 0.88 \\
\hline Quality grade A+B & 1.24 & 1.09 & 1.43 \\
\hline $\begin{array}{l}\text { Spirometry experience } \\
\text { (per increment of 10 tests) }\end{array}$ & 0.97 & 0.96 & 0.99 \\
\hline
\end{tabular}

$\mathrm{FEV}_{1}$ : forced expiratory volume in 1 second; FVC: forced vital capacity; $\mathrm{Cl}$ : confidence interval. Age = age at examination; Sex (male vs. female); Spirometry experience $=$ number of tests performed by the GP prior actual test. The co-variates obesity, consultation reason, having dyspnoea, having cough, having sputum were included in the model but are not displayed as the $95 \% \mathrm{Cl}$ is including 1 .

limitation (data not shown). Similarly, there was no relation between the reason for the consultation and lung function at the lower grades of airflow limitation, although consultations for respiratory reasons tended to increase at higher grades of airflow limitation (data not shown).

The results of multivariate logistic regression analysis in order to determine the factors that contribute to obstruction (low $\mathrm{FEV}_{1} / \mathrm{FVC}$ ratio and $\mathrm{FEV}_{1} \%$ predicted below $65 \%$ ) can be seen in Table 4.

\section{Discussion}

The findings of this study indicate a prevalence of aifflow limitation of approximately $29 \%$ among smokers aged $\geq 40$ years in Switzerland, and 58\% of them reported at least one current respiratory symptom. However, lung function did not differ in individuals who reported respiratory symptoms compared to those who did not. In multivariate logistic regression analysis, age, sex, obesity, spirometry quality grade and GPs' spirometry experience were associated with clinically relevant airway obstruction.

We used pre- rather than post-bronchodilator spirometry to identify patients with possible COPD, otherwise using the GOLD/Hardie classification. ${ }^{1,14,15}$ This may have led to an overestimation of its prevalence in the study population since subjects with fully reversible airflow limitation - and therefore not meeting the GOLD criteria of COPD - may have been wrongly included. ${ }^{18}$ As ageing affects lung volumes, overdiagnosis of COPD in elderly patients is likely when using an $\mathrm{FEV}_{1} / \mathrm{FVC}$ ratio $<0.7$ to define obstructive lung disease. To minimise misclassification we used different $\mathrm{FEV}_{1} / \mathrm{FVC}$ ratios to classify obstruction for patients $\geq 70$ years; for the logistic regression analysis, however, we selected patients in whom the $\mathrm{FEV}_{1} / \mathrm{FVC}$ ratio was $<0.7$ and the $\mathrm{FEV}_{1} \%$ predicted $<65 \%$. Another possibility to avoid misclassification is the use of LLN values for $\mathrm{FEV}_{1} / \mathrm{FVC}$ and $\mathrm{FEV}_{1}$ when interpreting pulmonary function tests. ${ }^{19}$ The use of reversibility testing alone to differentiate between asthma and COPD is not appropriate. ${ }^{20}$ Some older patients with asthma may have beta-adrenergic dysfunction and therefore will respond poorly to short-acting beta-adrenergic bronchodilators ${ }^{21}$ whereas others need a prolonged course with oral steroids ${ }^{20}$ in order to show improvement in lung function. Patients with a longstanding history of asthma often show limited reversibility as a result of chronic airway inflammation, or both diseases may be present in the same patient..$^{20}$ Patient history, including symptoms, development over time, exposure, atopy and family history, will therefore often contribute more to the correct diagnosis than lung function testing alone. ${ }^{20,22}$ Furthermore, smoking is an independent risk factor for asthma as well as COPD, and patients with or without airflow limitation should benefit from smoking cessation intervention.

The quality-controlled, auto-feedback, factory-calibrated spirometer provides an easy, time-efficient and good quality tool for office spirometry, which allows screening in a large population of people at risk of COPD. However, even with use of such a spirometer, only $60 \%$ of traces in the whole sample were of satisfactory quality. Performing spirometry prior to, and after, administration of a short-acting bronchodilator, however, is much more time consuming; therefore, the screening is less likely to be performed in all patients at risk, especially if their reason for presentation is for reasons other than respiratory symptoms. The use of an agent with potential adverse effects is also debatable when asymptomatic individuals are tested, even though shortacting $\beta_{2}$-agonists (e.g. salbutamol) are sold as over-the-counter drugs in some countries. Nevertheless, as shown below, patients in this group are equally likely to present with moderate to severe airflow limitation and need to be identified. We therefore suggest pre-bronchodilator spirometry as an appropriate method to exclude COPD in a GP setting. Patients with a low $\mathrm{FEV}_{1} / \mathrm{FVC}$ ratio and less than $65 \% \mathrm{FEV}_{1} \%$ predicted should undergo postbronchodilator spirometry thereafter to diagnose asthma if the obstruction is reversible, or if not, to classify the patients correctly and to optimise therapy given the severity of the disease.'

Estimates of the prevalence of COPD among smokers show considerable variation, depending on the COPD definition used (British Thoracic Society [BTS], European Respiratory Society [ERS], ATS, GOLD), ${ }^{23}$ and on factors such as age, gender, smoking habits, environmental exposure and ethnicity; therefore prevalence rates cannot easily be compared. In Europe, the prevalence of COPD ranges between 13\% (UK) and $46 \%$ (Belgium, Poland). ${ }^{24-28}$ However, recent studies show that even after elimination of the known influencing factors, considerable national differences in prevalence remain unexplained and should be the subject of further investigations. ${ }^{18}$

Symptoms of cough, sputum production and dyspnoea were 
distributed fairly evenly across our study population, independent of the presence and severity of airflow limitation, and asymptomatic subjects were as equally likely to present with airflow limitation as symptomatic ones. Only moderate to severe dyspnoea showed a higher prevalence in patients with very severe airflow limitation. These findings contrast with those from other studies, ${ }^{9}$ and highlight the importance of using validated symptom questionnaires in diagnostic screening. We cannot exclude a potential information bias as physicians might have recorded their patients' answers on the spirometry print out form after being aware of the spirometry results. If this is the case the correlation of symptoms with spirometry abnormalities would be even smaller in reality. Secondary selection bias is also likely to have occurred: those patients in whom data on respiratory symptoms were available were more often classified as having 'normal spirometry' or 'mild obstruction' compared to patients whose spirometries were performed but with no accompanying recorded data on respiratory symptoms. ${ }^{10}$ Therefore, our findings need to be interpreted with care before generalising to the whole population of patients with COPD in primary care. Cough, sputum production and dyspnoea are individual factors that vary in intensity over time. Therefore, classification bias might have occurred as some patients declared to the physician symptoms they encountered during the last 24 hours whereas others referred to the symptoms they had on the day of the exam. The same might be true for the recording of the symptoms by the GPs.

According to GOLD guidelines, in COPD, mucus hypersecretion, airflow limitation, air trapping and hyperinflation, gas exchange abnormalities and cor pulmonale may occur, and moderate to severe COPD is nowadays considered to be a systemic disease with findings such as cachexia, skeletal muscle wasting, cardiovascular disease, anaemia, osteoporosis and depression. ${ }^{1}$ Respiratory symptoms such as cough, dyspnoea and sputum production are very unspecific and may or may not be present in subjects with airflow limitation. Subjects in whom there is a predominant distortion of gas exchange may have more dyspnoea, but may complain of less cough and sputum production. Subjects can have other diseases that cause these unspecific symptoms and may over- or under-report these symptoms. Our findings suggest that respiratory symptoms, when elicited by brief unvalidated questions, are neither adequate to detect COPD nor to determine the severity of the disease, which reflects the fact that the diagnosis of COPD is, by definition, based on spirometry and does not take into account elements like chronic bronchitis and emphysema. This is not in concordance with past studies using questionnaires to screen for COPD. ${ }^{8,9}$ Even when using the St George's Respiratory Questionnaire (a frequently used multidimensional health status questionnaire for COPD) the subscores and total scores only weakly correlate with $\mathrm{FEV}_{1}$ and
FVC. ${ }^{29}$ COPD patients with moderate to severe obstruction, therefore, need a tailored investigation incorporating not only simple spirometry, but eventually a referral to a specialist investigator, to determine residual volumes with body plethysmography, carbon monoxide (CO) diffusion capacity, 6minute walking distance and sometimes pulmonary arterial pressure measurement in order to guide therapy. ${ }^{1}$

The observation that the primary reason for consultation generally was not due to respiratory problems supports the recommendation that spirometry should be performed routinely for all smokers aged over 40 years, irrespective of their reason for attending the GP's office. The GOLD guidelines suggest that all subjects either presenting with respiratory symptoms, or with a history of exposure to risk factors, be screened for COPD by spirometry. For assessment of COPD severity only, spirometric classification should be complemented by the severity of the patient's symptoms, the degree to which they affect the patient's daily life, the patient's exercise impairment, and the presence of complications. ${ }^{1}$ Our findings highlight the fact that patients only see their GP for respiratory symptoms in the late stages of obstructive airway disease, and therefore physicians should actively look for airflow limitation and COPD in high risk patients.

The findings from logistic regression suggest that the risk for obstruction increases with age and is higher for males than for females, which is in concordance with other studies investigating the prevalence of COPD in primary care..$^{30,31}$ However, as discussed above, when using arbitrary cut-off points, overdiagnosis of COPD in elderly individuals is likely and these results need to be interpreted with care. Good quality spirometries (grade A-B) were associated with obstruction, probably because the end-of-test criteria were more likely to be satisfied than in those with lower spirometry quality. ${ }^{32}$ Obstruction was negatively associated with increasing numbers of spirometries. We have already reported that the quality grade of spirometries performed by GPs can vary according to training: GPs who performed fewer than 10 tests had the lowest mean quality grade recorded, whereas the highest quality grades were achieved by GPs who had performed between 21 and 30 tests. The quality was even lower in those who performed more spirometries, suggesting that refresher training might be important to maintain a good standard..$^{10}$

Overall, this study shows that airflow limitation is a frequent condition among smokers and that patient-reported respiratory symptoms do not correlate with spirometry findings. Good quality spirometries as well as increasing age are positively associated with obstruction, whereas female sex and increasing number of spirometries performed were negatively associated. Pre-bronchodilator spirometry is a practical method for early identification of patients with airflow limitation, allowing earlier diagnosis and intervention in patients with possible COPD. However, poor quality of spirometry in primary care, even with an 
automated feedback and quality control spirometer, remains a major issue.

\section{Acknowledgements}

The authors acknowledge the valuable suggestions regarding post-hoc data analysis by the editor and referees of the Primary Care Respiratory Journal, and Dr David Macari of PAREXEL MMS for his support in the preparation of the manuscript (financed jointly by Boehringer Ingelheim $\mathrm{GmbH}$ and Pfizer AG).

\section{Funding declaration}

The study was supported financially by a grant from Boehringer Ingelheim (Switzerland) GmbH, Basel, and Pfizer (Switzerland) AG, Zurich.

\section{Conflict of interest declaration}

D. Miedinger and J.D. Leuppi have received free spirometric equipment from ndd Medizintechnik AG for other research studies. C. Buess is responsible for Research and Development at ndd Medizintechnik AG.

A. Linz, C. Praehauser, P.N. Chhajed, S. Schafroth Török, H. C. Bucher and M. Tamm have no conflicts to disclose.

Participating physicians were provided with an EasyOne ${ }^{\mathrm{TM}}$ spirometer with disposable mouthpieces without charge for this study. Physicians were allowed to keep the spirometer at the end of the study without charge.

\section{References}

1. Global Initiative for Chronic Obstructive Lung Disease - Global strategy for the diagnosis, management, and prevention of chronic obstructive pulmonary disease. Update 2009. www.goldcopd.com

2. Celli BR, MacNee W. Standards for the diagnosis and treatment of patients with COPD: a summary of the ATS/ERS position paper. Eur Respir J 2004;23(6):932-46. http://dx.doi.org/10.1183/09031936.04.00014304

3. Peters JM, Ferris BG, Jr. Smoking, pulmonary function, and respiratory symptoms in a college-age group. Am Rev Respir Dis 1967;95(5):774-82.

4. Wilt TJ, Niewoehner D, Kane RL, MacDonald R, Joseph AM. Spirometry as a motivational tool to improve smoking cessation rates: a systematic review of the literature. Nicotine Tob Res 2007:9(1):21-32. http://dx.doi.org/10.1080/ 14622200601078509

5. Sundblad BM, Larsson K, Nathell L. Lung function testing influences the attitude toward smoking cessation. Nicotine Tob Res 2010;12(1):37-42 (Epub 2009 Nov 19).

6. Tinkelman DG, Price D, Nordyke RJ, Halbert RJ. COPD screening efforts in primary care: what is the yield? Prim Care Resp J 2007;16(1):41-8. http://dx.doi.org/10.3132/pcri.2007.00009

7. Derom E, van Weel C, Liistro G, et al. Primary care spirometry. Eur Respir $J$ 2008;31(1):197-203. http://dx.doi.org/10.1183/09031936.00066607

8. Calverley PM, Nordyke RJ, Halbert RJ, Isonaka S, Nonikov D. Development of a population-based screening questionnaire for COPD. COPD 2005;2(2):225-32.

9. Price DB, Tinkelman DG, Halbert RJ, et al. Symptom-based questionnaire for identifying COPD in smokers. Respiration 2006;73(3):285-95. http://dx.doi.org/ 10.1159/000090142

10. Leuppi JD, Miedinger D, Chhajed PN, et al. Quality of spirometry in primary care for case finding of airway obstruction in smokers. Respiration 2010;79(6):469-74 (Epub 2009 Sept 26).

11. Standardization of Spirometry, 1994 Update. American Thoracic Society. Am J Respir Crit Care Med 1995;152(3):1107-36.

12. Ferguson GT, Enright PL, Buist AS, Higgins MW. Office spirometry for lung health assessment in adults: a consensus statement from the National Lung Health Education Program. Respir Care 2000;45(5):513-30.

13. Brandli O, Schindler C, Kunzli N, Keller R, Perruchoud AP. Lung function in healthy never smoking adults: reference values and lower limits of normal of a Swiss population. Thorax 1996;51(3):277-83. http://dx.doi.org/10.1136/ thx.51.3.277

14. Fabbri LM, Hurd SS. Global Strategy for the Diagnosis, Management and Prevention of COPD: 2003 update. Eur Respir J 2003;22(1):1-2. http://dx.doi.org/ 10.1183/09031936.03.00063703
15. Hardie JA, Buist AS, Vollmer WM, Ellingsen I, Bakke PS, Morkve O. Risk of overdiagnosis of COPD in asymptomatic elderly never-smokers. Eur Respir J 2002;20(5):1117-22. http://dx.doi.org/10.1183/09031936.02.00023202

16. Surveillance for respiratory hazards in the occupational setting [American Thoracic Society]. Am Rev Respir Dis 1982;126(5):952-6.

17. Hamacher J, Buchi S, Georgescu CL, et al. Improved quality of life after lung volume reduction surgery. Eur Respir J 2002;19(1):54-60. http://dx.doi.org/10.1183/ 09031936.02.00462001

18. Vollmer WM, Gislason T, Burney $\mathrm{P}$, et al. Comparison of spirometry criteria for the diagnosis of COPD: results from the BOLD Study. Eur Respir J 2009;34(3):588-97 (Epub 2009 May 21).

19. Levy ML, Quanjer PH, Booker R, Cooper BG, Holmes S, Small I. Diagnostic spirometry in primary care: Proposed standards for general practice compliant with American Thoracic Society and European Respiratory Society recommendations: a General Practice Airways Group (GPIAG)' document, in association with the Association for Respiratory Technology \& Physiology (ARTP) ${ }^{2}$ and Education for Health ${ }^{3}$ 'www.gpiag.org ${ }^{2}$ www.artp.org ${ }^{3}$ www.educationforhealth.org.uk. Prim Care Resp J 2009;18(3):130-47.

20. Chotirmall SH, Watts M, Branagan P, Donegan CF, Moore A, McElvaney NG. Diagnosis and management of asthma in older adults. I Am Geriatr Soc 2009;57(5):901-09. http://dx.doi.org/10.1111/j.1532-5415.2009.02216.x

21. Connolly MJ, Crowley JJ, Nielson CP, Charan NB, Vestal RE. Peripheral mononuclear leucocyte beta adrenoceptors and non-specific bronchial responsiveness to methacholine in young and elderly normal subjects and asthmatic patients. Thorax 1994;49(1):26-32. http://dx.doi.org/10.1136/ thx.49.1.26

22. Huss K, Naumann PL, Mason PJ, et al. Asthma severity, atopic status, allergen exposure and quality of life in elderly persons. Ann Allergy Asthma Immunol 2001;86(5):524-30. http://dx.doi.org/10.1016/\$1081-1206(10)62900-6

23. Lindberg $A$, Jonsson $A C$, Ronmark $E$, Lundgren $R$, Larsson $L G$, Lundback $B$. Prevalence of chronic obstructive pulmonary disease according to BTS, ERS, GOLD and ATS criteria in relation to doctor's diagnosis, symptoms, age, gender, and smoking habits. Respiration 2005;72(5):471-9. http://dx.doi.org/10.1159/ 000087670

24. de Torres JP, Campo A, Casanova C, Aguirre-Jaime A, Zulueta J. Gender and chronic obstructive pulmonary disease in high-risk smokers. Respiration 2006;73(3):306-10. http://dx.doi.org/10.1159/000090051

25. Kalucka S. The occurrence of chronic obstructive pulmonary disease (COPD) in cigarette smoking families. Przeg/ Lek 2006;63(10):848-57.

26. Shahab L, Jarvis MJ, Britton J, West R. Prevalence, diagnosis and relation to tobacco dependence of chronic obstructive pulmonary disease in a nationally representative population sample. Thorax 2006;61(12):1043-7. http://dx.doi.org/10.1136/ thx.2006.064410

27. Stratelis G, Jakobsson P, Molstad S, Zetterstrom O. Early detection of COPD in primary care: screening by invitation of smokers aged 40 to 55 years. $\mathrm{Br} / \mathrm{Gen}$ Pract 2004;54(500):201-06

28. Vandevoorde J, Verbanck S, Gijssels L, et al. Early detection of COPD: a case finding study in general practice. Respir Med 2007;101(3):525-30. http://dx.doi.org/ 10.1016/j.rmed.2006.06.027

29. Meguro M, Barley EA, Spencer S, Jones PW. Development and Validation of an Improved, COPD-Specific Version of the St. George Respiratory Questionnaire. Chest 2007;132(2):456-63. http://dx.doi.org/10.1378/chest.06-0702

30. van Schayck CP, Loozen JM, Wagena E, Akkermans RP, Wesseling GJ. Detecting patients at a high risk of developing chronic obstructive pulmonary disease in general practice: cross sectional case finding study. BMJ 2002;324(7350):1370. http://dx.doi.org/10.1136/bmj.324.7350.1370

31. Tinkelman DG, Price DB, Nordyke RJ, et al. Symptom-based questionnaire for differentiating COPD and asthma. Respiration 2006;73(3):296-305. http://dx.doi.org/ 10.1159/000090141

32. Eaton T, Withy S, Garrett JE, Mercer J, Whitlock RM, Rea HH. Spirometry in primary care practice: the importance of quality assurance and the impact of spirometry workshops. Chest 1999;116(2):416-23. http://dx.doi.org/10.1378/ chest.116.2.416 